\title{
EXAMINING THE EFFECTS OF THE COVID-19 LOCKDOWNS ON REDUCING POLLUTANT CONCENTRATIONS IN US URBAN AREAS: EVIDENCE FROM LOS ANGELES, SEATTLE AND NEW YORK CITY
}

\author{
EDWARD WEI \\ University of Virginia, USA
}

\begin{abstract}
Reductions in air pollution benefit the health of both humanity and the environment. Understanding the contributing factors to air pollution is critical for devising actions aimed at reducing pollution. This study examines the effectiveness of the 2020 COVID-19 lockdowns in reducing air pollution in US urban environments. It focuses on three cities - Los Angeles, Seattle, and New York City - and utilizes city-level daily pollutant data for carbon monoxide $(\mathrm{CO})$, nitrogen dioxide $\left(\mathrm{NO}_{2}\right)$, ozone $\left(\mathrm{O}_{3}\right)$, and particulate matter smaller than 2.5 microns $\left(\mathrm{PM}_{2.5}\right)$. Each city had three time periods (pre-lockdown, lockdown, and post-lockdown) determined by the enactment and relaxation of gathering restrictions. T-tests were used to compare air pollution measured during the three periods against a baseline created from the mean pollutant concentrations from 2015 to 2019. The results show that the lockdowns were effective in reducing $\mathrm{CO}$ concentrations in all three cities. Reductions in $\mathrm{NO}_{2}$ during lockdowns were supported by results from New York and Seattle, the cities with colder and more humid climates. Only Los Angeles, the warmest and driest city, saw reductions in $\mathrm{O}_{3}$ concentrations during the lockdowns. Reductions in $\mathrm{PM}_{2.5}$ concentrations during lockdowns were observed in Los Angeles and New York, but not in Seattle. These findings support devising policies to reduce $\mathrm{CO}, \mathrm{NO}_{2}$, and $\mathrm{PM}_{2.5}$ through discouraging private vehicle travel in large urban areas. The research also suggests that those policies' effectiveness is varied for each pollutant type and climate.
\end{abstract}

Keywords: air pollution, lockdowns, COVID-19, health, urban environments.

\section{INTRODUCTION}

Air pollution is directly responsible for over 4.2 million deaths per year as well as many types of lung diseases and cancers [1]. Labelled a leading cause of death worldwide by the World Health Organization (WHO), air pollution is also responsible for worsening environmental phenomenon such as wildfires and acidic rain, which, in turn lead to additional health risks and environmental damage [2]. The reduction of air pollution is a necessity for the health of the planet and sustainability of humanity.

Among many factors, emission from transportation is the largest contributor to air pollution, followed closely by electricity production and industrial activities [3]. Thus, policy solutions to air pollution often include implementing stringent emission standards and reducing automobile travel.

From late Winter to Spring 2020, numerous US cities experienced their sharpest decline in consumer transportation in over 30 years, a result of "lockdowns" enacted in response to the COVID-19 pandemic [4]. At the same time, news media reported an increase in the 'clarity' of the atmosphere, quickly attributing it to the lockdowns' effects in reducing consumer and industry activities [5], [6].

If the COVID-19 lockdowns are effective in reducing air pollution via reductions in civilian and industry activity, then it may be worthwhile to investigate policies similar to lockdown restrictions, i.e., activity-controlling policies, to improve the air quality of communities. 
However, determining the effects of the COVID-19 lockdowns on air pollution is difficult because of a seasonal pattern of air pollution, which many of those casual observations of air quality change fail to account for. Urban air pollution tends to clear up from a colder season (e.g., winter) to a warmer one (e.g., spring) due to changes in urban activities and weather [7]. A study done in 2018 found that rural-residential coal combustion (RRCC), a seasonal activity that occurs mostly in the winter, contributed to over $60 \%$ of groundlevel particulate emissions in residential areas of Shandong, China during that season [8]. Similarly, data from the US Environmental Protection Agency shows trends of decreasing concentrations of carbon monoxide and nitrogen dioxide from winter to spring in many US cities [7].

Therefore, the perceived improvements in air quality during the COVID-19 lockdowns relative to the months before them may not be sufficient evidence for the lockdowns' effects on air pollution, because the lockdowns coincided with the transition from winter to spring.

Consequently, this study seeks to find the effects (not the feasibility) of the COVID19 lockdowns on air quality in urban environments. The findings could be informative for policymakers and urban planners as they consider how to promote urban sustainability and health.

\section{MATERIALS AND METHODOLOGY}

\subsection{Study areas}

Three cities were examined in this study: Los Angeles, New York City, and Seattle. These cities were chosen based on climate, population density, and data availability. Table 1 shows the details of the chosen cities.

Table 1: City details.

\begin{tabular}{c|c|c}
\hline & Population density [9] $\left(\right.$ people $\left./ \mathrm{km}^{2}\right)$ & Climate [10] \\
\hline Los Angeles & 2,700 & Hot, Dry \\
New York City & 10,800 & Temperate, Humid \\
Seattle & 3,500 & Temperate, Wet \\
\hline
\end{tabular}

Each of the cities underwent a roughly 3-month-long lockdown period when policies were enacted to restrict civilian activities. This study defines that a city's lockdown period started when the city/state government issued a stay-at-home order; and the lockdown period ended when those orders were lifted or relaxed. The study time frame was then divided into three periods based on lockdown dates specific to each city: pre-lockdown, lockdown, and post-lockdown. Time periods for each city are shown in Table 2.

Table 2: Lockdown period classifications by city.

\begin{tabular}{c|c|c|c}
\hline & Pre-lockdown & Lockdown & Post-lockdown \\
\hline Los Angeles [11], [12] & 1 Jan.-19 Mar. & 19 Mar.-24 May & 24 May-1 Aug. \\
New York City [13], [14] & 1 Jan.-22 Mar. & 22 Mar.-8 Jun. & 8 Jun.-1 Aug. \\
Seattle [15], [16] & 1 Jan.-11 Mar. & 11 Mar.-1 Jun. & 1 Jun.-1 Aug. \\
\hline
\end{tabular}




\subsection{Data sources}

The pollutants examined were daily concentrations of carbon monoxide (measured in parts per million $\mathrm{CO}$ ), nitrogen dioxide (AQI points $\mathrm{NO}_{2}$ ), ozone (AQI points $\left.\mathrm{O}_{3}\right)$, and particulate matter smaller than 2.5 microns $\left(\mu \mathrm{g} / \mathrm{m}^{3} \mathrm{PM}_{2.5}\right)$. The US Environmental Protection Agency (EPA) defines Air Quality Index (AQI) as a scale that measures the concentration of the pollutant relative to their health concerns [7]. Data for pollutant concentrations came from the World Air Quality Index (WAQI) project. The WAQI is a non-profit organization that aggregates air quality data from local governments and agencies in cities around the world. This study uses data collected by the following agencies: the New York State Department of Environmental Conservation (NYSDEC), California Air Resources Board (CARB), and Washington State Department of Ecology. Data was collected in 24-hour averages at the city level from roughly 60 sensors distributed evenly throughout each city.

\subsection{Analysis and hypothesis}

A series of 2-sample paired t-tests were conducted to examine if an air pollutant's concentration levels during 2020 lockdowns were significantly different from its baseline conditions of matching timespans. The baseline conditions were estimated by averaging corresponding pollutant concentrations over a 5-year window (2015-2019). The purpose of these statistical analyses was to examine whether changes in a pollutant's concentrations existed independent of the impacts of potential seasonal factors underlying the transition of those periods. Considering that seasonal patterns likely impacted how lockdowns affected air pollution, the following hypothesis was developed and tested: A pollutant's concentration level is significantly lower than its baseline during the in-lockdown period. The pre-lockdown and post-lockdown periods' comparisons can help provide context for understanding the magnitude of the difference between 2020 and the baseline.

\section{RESULTS AND DISCUSSION}

The results of the t-tests are presented graphically using pairs of boxplots. The darker boxplot represents the distribution of observations during the baseline period (2015-2019), while the white boxplot represents the distributions of observations during 2020 (the lockdowns). Summary statistics for each pair of boxplots' comparison are shown, with $\Delta x$ representing the difference in means between a 2020 period and its corresponding baseline, $p$ the significance level of the mean difference, $\Delta M$ the change in median, $M_{1}$ the median of observations during the baseline, $M_{2}$ the median of observations during 2020, and $n$ the number of paired observations.

\subsection{Los Angeles}

In all three periods (pre-lockdown, lockdown, and post-lockdown), Los Angeles saw significant reductions in mean $\mathrm{CO}$ concentrations in this year compared to the baseline conditions. The pre-lockdown mean CO concentration had a significant decrease of $1.24 \mathrm{ppm}$ $(p<0.001)$, the lockdown period had a significant decrease of $1.47 \mathrm{ppm}(p<0.001)$, and the post-lockdown period had a significant decrease of $0.84 \mathrm{ppm}(p<0.001)$. The largest reduction was during the lockdown period. The data support the hypothesis that the lockdowns were effective in reducing pollution (Fig. 1).

The mean nitrogen dioxide $\left(\mathrm{NO}_{2}\right)$ concentration during the pre-lockdown period had a significant increase of 7.17 AQI points above the baseline $(p<0.001)$, while the lockdown 
Pollutants in Los Angeles by Lockdown Period

(Pre-Lockdown: 1/1-3/19 In Lockdown: 3/19-5/24 Post-Lockdown: 5/24-8/1)
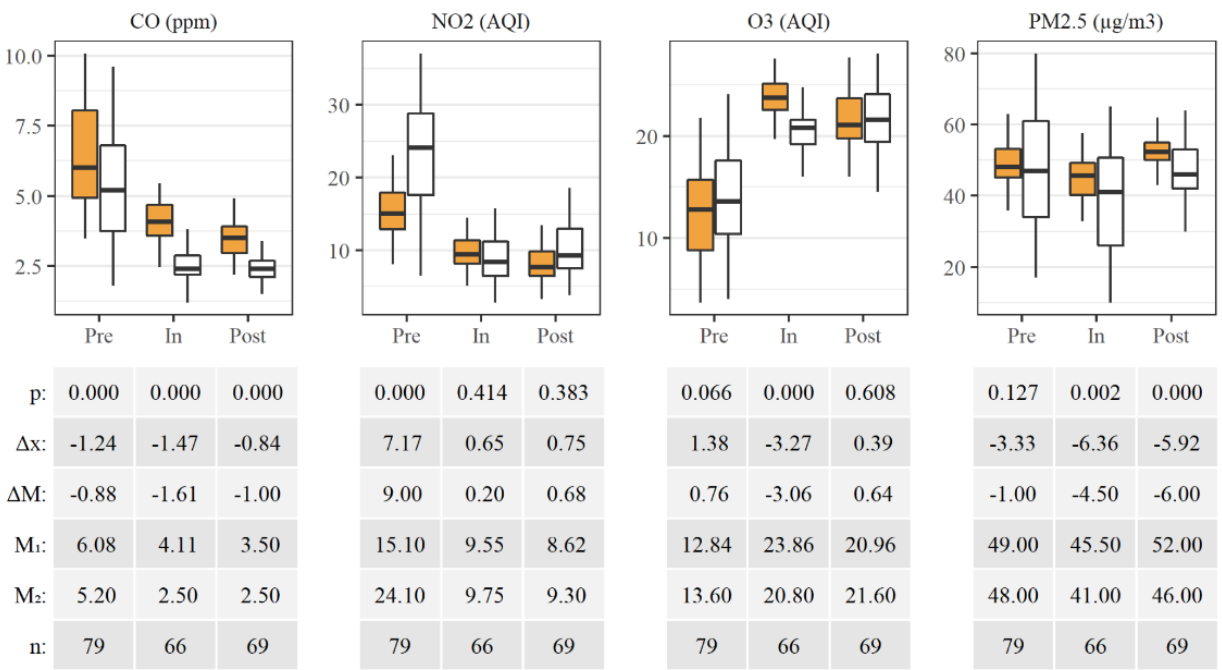

Figure 1: Pollutants in Los Angeles by lockdown period.

and post-lockdown periods had no significant changes in mean concentration. The drying of soil in warm, dry climates emits $\mathrm{NO}_{2}$ [17], which could offset $\mathrm{NO}_{2}$ reductions due to activity changes and explain how $\mathrm{NO}_{2}$ concentrations did not change significantly. The reduction in mean $\mathrm{NO}_{2}$ concentrations from the pre-lockdown period to the lockdown period was significantly larger than the baseline, supporting the hypothesis of the effectiveness of the lockdown. However, when lockdown measures were relaxed, $\mathrm{NO}_{2}$ levels did not return to higher-than-baseline values (similar to the pre-lockdown period). A possible explanation could be that the $\mathrm{NO}_{2}$ emitting activities may not have fully recovered following the relaxation of restrictions.

Mean ozone $\left(\mathrm{O}_{3}\right)$ concentrations in Los Angeles observed no significant change in tte pre-lockdown and post-lockdown periods compared to their respective baselines. The lockdown period observed a significant decrease in mean $\mathrm{O}_{3}$ concentrations of $3.27 \mathrm{AQI}$ points $(p<0.001)$ relative to the baseline. The only significant decrease being during the lockdown periods provides supporting evidence that the lockdown was one of the factors that caused a reduction in this pollutant.

Mean particulate matter smaller than 2.5 microns $\left(\mathrm{PM}_{2.5}\right)$ concentrations in Los Angeles were significantly lower in the lockdown and post-lockdown period. The pre-lockdown mean concentration of $\mathrm{PM}_{2.5}$ was not significantly different from the baseline. During the lockdown period, mean $\mathrm{PM}_{2.5}$ levels had a significant decrease of $6.36 \mu \mathrm{g} / \mathrm{m}^{3}(p<0.05)$ relative to the baseline. During the post-lockdown period, $\mathrm{PM}_{2.5}$ decreased $5.92 \mu \mathrm{g} / \mathrm{m}^{3}(p<0.001)$. This supports the hypothesis that the lockdown was effective in reducing pollutant concentrations and suggests that activities did not return to normal following the relaxation of restrictions, since there was still a significant reduction in $\mathrm{PM}_{2.5}$ concentrations relative to baseline conditions. 
Pollutants in New York by Lockdown Period Baseline (5yr mean) 宁 2020

(Pre-Lockdown: 1/1-3/22 In Lockdown: 3/22-6/8 Post-Lockdown: 6/8-8/1)
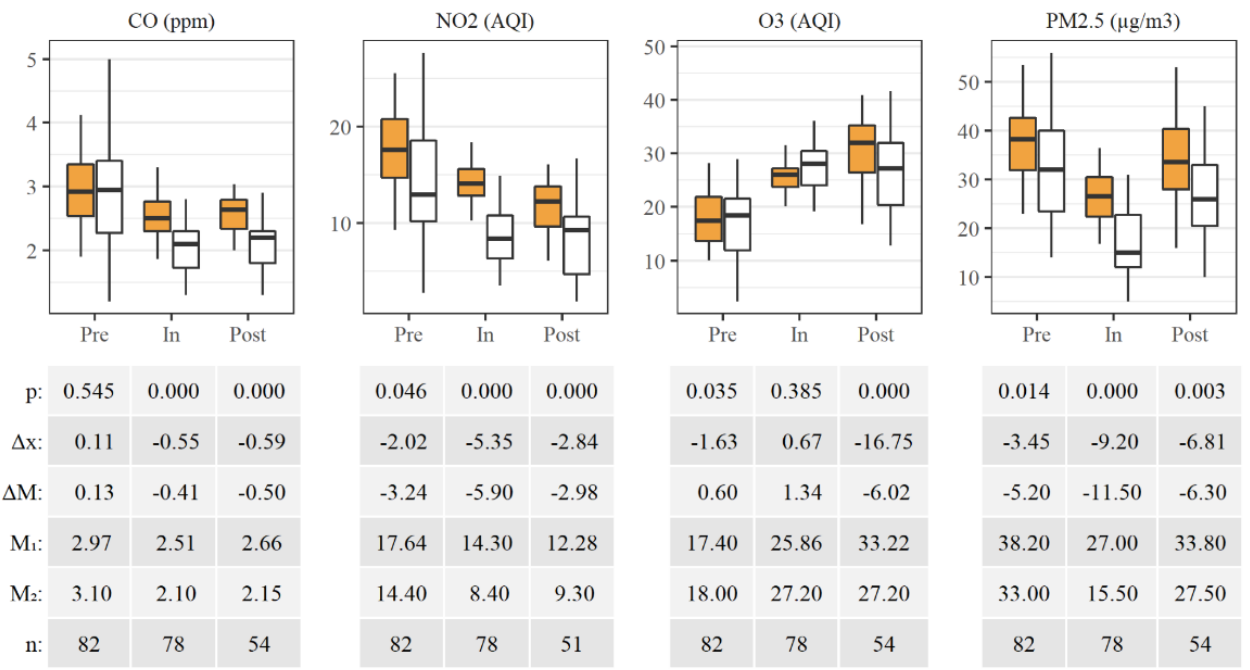

Figure 2: Pollutants in New York by lockdown period.

Overall, mean pollutant concentrations during the lockdown period in Los Angeles were significantly lower than their respective baselines. Similar reductions were present after the lockdowns for $\mathrm{CO}$ and $\mathrm{PM}_{2.5}$ only. A possible explanation for why only these two pollutants observed a "lingering" impact from the lockdowns is their connection to automobile use, which may not have returned to normal levels following the relaxation of lockdown measures. The climate of Los Angeles is dry and lacks frequent rainfall that can potentially clean the atmosphere. This could allow the effects of emission reduction to remain more evident in the atmosphere. The findings in Los Angeles provide support for the hypothesis that the lockdowns were effective in reducing air pollution for all pollutants, even more so for $\mathrm{CO}$ and $\mathrm{PM}_{2.5}$.

\subsection{New York}

Mean carbon monoxide (CO) concentrations in New York were lower than baseline levels during the lockdown and post-lockdown period. Pre-lockdown CO concentrations were not significantly different than the baseline. During the lockdown period, the mean CO concentration was $0.55 \mathrm{ppm}$ lower than the baseline $(p<0.001)$. During the post-lockdown period, $\mathrm{CO}$ concentrations were $0.59 \mathrm{ppm}$ lower than the baseline $(p<0.001)$. This pattern is similar to the observation of mean $\mathrm{PM}_{2.5}$ concentrations in Los Angeles, where the reductions in pollutant concentrations during the lockdown period were also present in the post-lockdown period (Fig. 2).

Overall, mean nitrogen dioxide $\left(\mathrm{NO}_{2}\right)$ concentrations in New York were significantly lower than the baseline in all three periods, contrary to observations in Los Angeles. In the pre-lockdown period, the mean concentration of $\mathrm{NO}_{2}$ was $2.02 \mathrm{AQI}$ points lower than the baseline $(p<0.05)$. During the lockdown, mean $\mathrm{NO}_{2}$ concentrations were significantly lower $(p<0.001)$ than the baseline by 5.35 AQI points. The mean post-lockdown period 
$\mathrm{NO}_{2}$ concentration was $2.84 \mathrm{AQI}$ points lower than the baseline $(p<0.001)$. Because the $\mathrm{NO}_{2}$ concentrations were lower throughout all periods examined, an external factor could have induced an overall decrease in pollutant concentration. However, the largest decrease (5.35 AQI points) in mean $\mathrm{NO}_{2}$ concentrations was during the lockdown period, which suggests that even in the presence of an external factor, the presence of a lockdown was effective in reducing the mean $\mathrm{NO}_{2}$ concentration. In the post-lockdown period, the reduction in mean $\mathrm{NO}_{2}$ concentration was larger than the pre-lockdown period by 0.82 AQI points. This suggests that reductions in $\mathrm{NO}_{2}$ emitting activities did not recover to levels before the lockdown.

Mean ozone $\left(\mathrm{O}_{3}\right)$ concentrations in New York were lower than the baseline prior to and following the lockdown. However, the mean $\mathrm{O}_{3}$ concentrations were not significantly different compared to the baseline during the lockdown period. In the pre-lockdown period, there was a 1.63 AQI point decrease in $\mathrm{O}_{3}$ concentrations compared to the baseline $(p<0.05)$. During the lockdown period, there was no significant change in $\mathrm{O}_{3}$ concentrations. There was a significant $(p<0.001)$ decrease in $\mathrm{O}_{3}$ concentrations of 16.75 AQI points following the lockdown. Large decreases in atmospheric $\mathrm{NO}_{2}$ concentrations induce increases in the formation of atmospheric $\mathrm{O}_{3}$ [18], which could explain the lack of $\mathrm{O}_{3}$ concentration decreases during the lockdown period.

The mean concentrations of particulate matter smaller than 2.5 microns $\left(\mathrm{PM}_{2.5}\right)$ in New York were lower than the baseline in all three periods examined. In the pre-lockdown period, there was a significant $(p<0.05)$ decrease of $0.014 \mu \mathrm{g} / \mathrm{m}^{3}$ in mean $\mathrm{PM}_{2.5}$ concentrations compared to the baseline. The mean concentration of $\mathrm{PM}_{2.5}$ during the lockdown period was $9.20 \mu \mathrm{g} / \mathrm{m}^{3}$ lower than the baseline $(p<0.001)$. In the post-lockdown period, the mean concentration of $\mathrm{PM}_{2.5}$ was $6.81 \mu \mathrm{g} / \mathrm{m}^{3}$ lower than the baseline $(p<0.05)$. The continued decrease in mean $\mathrm{PM}_{2.5}$ concentration compared to the baseline suggests that an external factor was present. However, the largest decrease in mean $\mathrm{PM}_{2.5}$ concentration $\left(9.20 \mu \mathrm{g} / \mathrm{m}^{3}\right)$ was during the lockdown period, similar to the trend observed for mean $\mathrm{PM}_{2.5}$ concentration in Los Angeles. This provides further evidence that the presence of lockdown was effective in reducing pollutant concentrations alongside other factors.

Mean $\mathrm{CO}, \mathrm{NO}_{2}$, and $\mathrm{PM}_{2.5}$ concentrations in New York were significantly $(p<0.05)$ lower than their respective baselines during the lockdown period. Following the lockdown period, mean concentrations for all pollutants examined were also significantly lower than their baselines. Mean $\mathrm{NO}_{2}$ and $\mathrm{PM}_{2.5}$ concentrations in New York were lower in all periods, but both experienced their largest decreases compared to their baselines during the lockdown periods. The findings from New York provide further evidence that the lockdowns were effective in reducing $\mathrm{CO}, \mathrm{NO}_{2}$, and $\mathrm{PM}_{2.5}$. Ozone concentrations were not positively impacted by the presence of lockdown relative to the baseline. A possible explanation is the interaction of atmospheric $\mathrm{NO}_{2}$ and $\mathrm{O}_{3}$ as mentioned above.

\subsection{Seattle}

Mean carbon monoxide (CO) concentrations in Seattle were lower than the baseline in the pre-lockdown and lockdown periods but increased following the lockdown. In the pre-lockdown period, the mean $\mathrm{CO}$ concentration was $1.63 \mathrm{ppm}$ lower than the baseline $(p<0.001)$. During the lockdown, there was a significant $(p<0.001)$ decrease in mean $\mathrm{CO}$ concentration of $1.47 \mathrm{ppm}$ compared to the baseline. However, in the post-lockdown period, mean $\mathrm{CO}$ levels were $0.63 \mathrm{ppm}$ higher than the baseline $(p<0.05)$. The immediate rebound in mean $\mathrm{CO}$ levels following the relaxation of the lockdown measures suggests that 
Pollutants in Seattle by Lockdown Period

Baseline (5yr mean) 它 2020

(Pre-Lockdown: 1/1-3/11 In Lockdown: 3/11-6/1 Post-Lockdown: 6/1-8/1)
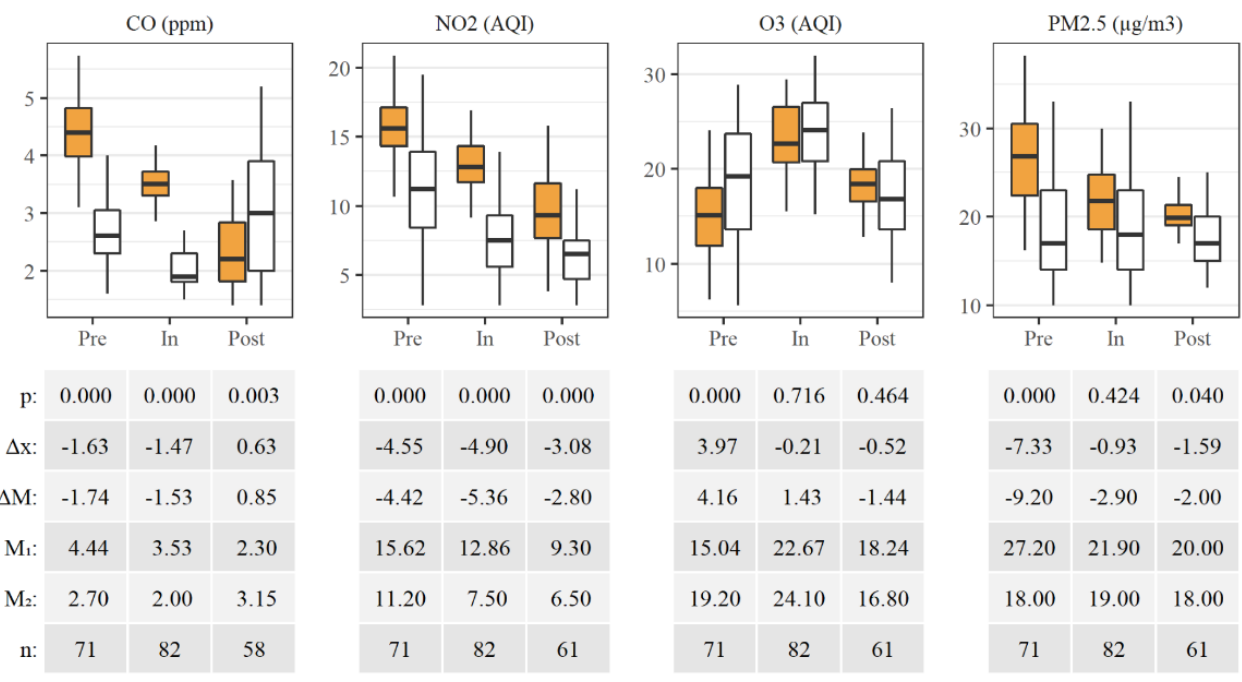

Figure 3: Pollutants in Seattle by lockdown period.

the lockdown presence was effective in reducing some amount of pollutant emission, and following the relaxation of the lockdown, immediately stopped suppressing pollution (Fig. 3).

The mean nitrogen dioxide $\left(\mathrm{NO}_{2}\right)$ levels in Seattle were significantly lower than the baseline in all periods examined. In the pre-lockdown period, the mean $\mathrm{NO}_{2}$ concentration was 4.55 AQI points lower than the baseline $(p<0.001)$. During the lockdown, there was a $4.90 \mathrm{AQI}$ point decrease in $\mathrm{NO}_{2}$ concentrations compared to the baseline. After the lockdown, there was a decrease of $3.08 \mathrm{AQI}$ points compared to the baseline. The constant overall difference in mean concentration suggests that an external factor reduced overall $\mathrm{NO}_{2}$ emission for this year. The presence of lockdown was associated with the largest reduction in $\mathrm{NO}_{2}$ concentrations of all periods (4.90 AQI points).

There was no significant change in mean ozone $\left(\mathrm{O}_{3}\right)$ concentration during the lockdown and post-lockdown period in Seattle. In the pre-lockdown period, the mean $\mathrm{O}_{3}$ concentration was $3.97 \mathrm{AQI}$ points greater than the baseline $(p<0.001)$. Based on the results from New York, the significantly decreased $\mathrm{NO}_{2}$ concentration during the lockdown period would predict that the $\mathrm{O}_{3}$ concentrations would be much higher during the lockdown period, though, this was not the case. The presence of the lockdown could be the explanation for why the ozone concentrations were not higher than the baseline during the lockdown period. However, the data does not strongly support this hypothesis since increases/decreases in pollutant concentrations can rapidly switch directions (as shown $\mathrm{O}_{3}$ changes in Los Angeles).

There were significant decreases in mean particulate matter $\left(\mathrm{PM}_{2.5}\right)$ concentrations in all periods but the lockdown period in Seattle. In the pre-lockdown period, there was a significant $(p<0.001)$ decrease of $7.33 \mu \mathrm{g} / \mathrm{m}^{3}$ in the $\mathrm{PM}_{2.5}$ concentrations. During the lockdown period, there was no significant change in mean $\mathrm{PM}_{2.5}$ concentration compared to the baseline, whereas there was a $1.69 \mu \mathrm{g} / \mathrm{m}^{3}(p<0.05)$ decrease in mean $\mathrm{PM}_{2.5}$ during the post-lockdown period. The absence of change in $\mathrm{PM}_{2.5}$ concentration in response to 
the lockdown could suggest that the lockdowns were ineffective in reducing the pollutant. However, the levels of $\mathrm{PM}_{2.5}$ in Seattle are already incredibly low compared to the other cities examined, suggesting a 'diminishing returns' effect in Seattle when the lockdowns are coupled with the city's already low emissions. Seattle also observes frequent light rainfall, which can increase $\mathrm{PM}_{2.5}$ concentrations [19]. This could counteract the effectiveness of the lockdowns.

Pollutant concentration trends in Seattle were similar to the other examined cities in some areas. Mean pollutant concentrations were lower than their baselines for $\mathrm{CO}$ and $\mathrm{NO}_{2}$ during the lockdown period, but not for $\mathrm{O}_{3}$ nor $\mathrm{PM}_{2.5} \cdot \mathrm{O}_{3}$ concentrations in Seattle were increased during the pre-lockdown period but returned to the baseline level during the lockdown. $\mathrm{PM}_{2.5}$ concentrations were not reduced during the lockdown but were instead very low during the entire year. Seattle's extremely wet weather heavily impacts the reliability of data in measuring the impact of the lockdown because of the weather events that can potentially reduce pollution naturally. Seattle's findings strongly support the hypothesis that the lockdowns were effective in reducing $\mathrm{CO}$ and $\mathrm{NO}_{2}$ concentrations.

\section{CONCLUSION}

The aim of this research was to explore the effectiveness of the COVID-19 lockdowns in reducing pollutant concentrations in US cities. It was hypothesized that the lockdowns were effective in doing so.

Daily concentrations of carbon monoxide $(\mathrm{CO})$, nitrogen dioxide $\left(\mathrm{NO}_{2}\right)$, ozone $\left(\mathrm{O}_{3}\right)$, and particulate matter smaller than 2.5 microns $\left(\mathrm{PM}_{2.5}\right)$ were examined for three cities: Los Angeles, New York City, and Seattle. Data for each city was split into three periods: prelockdown, lockdown, and post-lockdown according to the date that lockdown policies were enacted. Pollutant concentrations were compared to a baseline created from the average of the concentrations from 2015-2019 during the same time periods using paired t-tests ( $\alpha=0.05)$.

Table 3 summarizes changes in mean pollutant concentrations from 2020 relative to the baseline (2015-2019) during the lockdown period for each city. Insignificant changes are replaced with NAs.

Table 3: Significant changes in mean pollutant concentrations during lockdown period of 2020 compared to $2015-2019$.

\begin{tabular}{c|c|c|c}
\hline & Los Angeles & New York & Seattle \\
\hline $\mathrm{CO}(\mathrm{ppm})$ & -1.47 & -0.55 & -1.47 \\
$\mathrm{NO}_{2}($ pts AQI $)$ & $\mathrm{NA}$ & -5.35 & -4.90 \\
$\mathrm{O}_{3}(\mathrm{pts} A Q \mathrm{I})$ & -3.27 & NA & NA \\
$\mathrm{PM}_{2.5}\left(\mu \mathrm{g} / \mathrm{m}^{3}\right)$ & -6.36 & -9.20 & NA \\
\hline
\end{tabular}

The results show that all three cities exhibited significant declines in $\mathrm{CO}$ concentrations during the lockdowns, consistent with results from other cities [20]-[22]. Vehicle and industrial activity are the largest sources of CO emissions in US cities [23], and significant declines in both during the lockdowns is very likely what resulted in decreased CO concentrations. Thus, it is reasonable to assume that activity-controlling policies could be effective in reducing $\mathrm{CO}$ concentrations in urban areas.

All cities except for Los Angeles experienced significant declines in $\mathrm{NO}_{2}$ concentrations during the lockdowns. The largest source of $\mathrm{NO}_{2}$ is from the burning of fuel, especially in vehicles [24]. Los Angeles experienced a much lower decrease in vehicle miles traveled 
during the lockdowns compared to New York and Seattle (a comparison of vehicle miles traveled (VMT) data provided by Streetlight Data for the three cities found that Los Angeles experienced a less than $20 \%$ decrease in VMT during the lockdowns, compared to New York and Seattle, both of which saw more than $40 \%$ decreases), which could explain the lack of a significant decrease in $\mathrm{NO}_{2}$ for this city. Another possible explanation could be that, in warm, dry climates, frequent drying of soil could emit $\mathrm{NO}_{2}$ [17] to offset reductions during the lockdown, and Los Angeles's climate is much warmer and dryer than the other cities examined. These findings could suggest two things: 1. For activity-controlling policies to be effective in reducing $\mathrm{NO}_{2}$, they must cause a significantly great decrease in vehicle travel. 2. Warm, dry climates could reduce the effectiveness of activity-controlling policies in reducing $\mathrm{NO}_{2}$.

In contrast to the observed $\mathrm{NO}_{2}$-change pattern, only Los Angeles exhibited declines in $\mathrm{O}_{3}$ concentrations during the lockdowns. Industrial and vehicle activity are sources of Volatile Organic Compounds (VOCs) that can form $\mathrm{O}_{3}$ [25]. However, Los Angeles did not experience as great a reduction in vehicle travel as the other cities (mentioned above), suggesting that vehicles may not play as significant a role in $\mathrm{O}_{3}$ formation in cities. Atmospheric $\mathrm{NO}_{2}$ and $\mathrm{O}_{3}$ are balanced in a rate reaction, where a decrease in one may induce an increase in the atmospheric production of the other [18]. It is possible that the $\mathrm{NO}_{2}$ reductions experienced by New York and Seattle had increased atmospheric $\mathrm{O}_{3}$ formation to offset any reduction in $\mathrm{O}_{3}$ resulting from declined vehicle uses during their respective lockdowns. These findings may not support activity-controlling policies as an effective method in reducing $\mathrm{O}_{3}$ concentrations, similar to findings in other cities [21], [22], [26]. Further research on the relationship between vehicle usage and $\mathrm{O}_{3}$ concentration is in need to inform policies addressing issues associated with this particular air pollutant.

$\mathrm{PM}_{2.5}$ concentrations were lower in all cities but Seattle. The largest source of $\mathrm{PM}_{2.5}$ emissions in cities is from power generation and vehicles [27]. The fact that Seattle's significant decline in vehicle usage didn't result in $\mathrm{PM}_{2.5}$ reduction has two possible explanations. First, this could be due to a 'diminishing returns' effect of $\mathrm{PM}_{2.5}$ reductions in Seattle's already extremely low baseline $\mathrm{PM}_{2.5}$ pollution. Second, Seattle's frequent, light rainfall during its lockdown period [28] could agitate ambient particles that may increase $\mathrm{PM}_{2.5}$ concentrations [19], which may offset any lockdown-induced $\mathrm{PM}_{2.5}$ reduction. The results suggest that activity-controlling policies may be somewhat effective in reducing $\mathrm{PM}_{2.5}$ concentrations in cities depending on local baseline situation and weather, which is in line with findings from other studies [20], [26], [29].

Overall, this study provides evidence supporting the hypothesis that the lockdowns were effective in improving air quality in general. It offers a nuanced understanding of how lockdowns could affect specific pollutants in urban environments. The lockdowns were most effective in reducing $\mathrm{CO}$ concentrations, somewhat effective in reducing $\mathrm{NO}_{2}$ and $\mathrm{PM}_{2.5}$ concentrations, and least effective in reducing $\mathrm{O}_{3}$ concentrations. The findings are applicable to most urban areas in the world and support devising policies to reduce $\mathrm{CO}, \mathrm{NO}_{2}$, and $\mathrm{PM}_{2.5}$ through discouraging private vehicle travel and promoting non-automobile transport. Since the feasibility of frequently implementing activity-controlling policies similar to the lockdowns is relatively low, policies that strongly encourages public transit usage and micromobility (e.g., walking, biking, scooters, etc) are likely successful to address $\mathrm{CO}, \mathrm{NO}_{2}$, and $\mathrm{PM}_{2.5}$ concentrations in many cities.

\section{ACKNOWLEDGEMENT}

I would like to express my appreciation to Dr. Nicole Ngo and Dr. Yizhao Yang, associate professors at the University of Oregon, for their guidance and encouragement. 


\section{REFERENCES}

[1] World Health Organization, Air Pollution, 2020.

[2] Department of Environmental Protection, Health and environmental effects of air pollution. Technical report, Commonwealth of Massachusetts Executive Office of Energy \& Environmental Affairs, 2016.

[3] US EPA, OAR, Sources of greenhouse gas emissions, 2015.

[4] U.S. Federal Highway Administration, Moving 12-month total vehicle miles traveled, 2020. FRED, Federal Reserve Bank of St. Louis.

[5] The Telegraph, Air quality improves in Delhi's 13 hotspots. 2020.

[6] Samaritan, S.G., Thanks to lockdown, air quality improves in Andhra Pradesh this year, 2020.

[7] US EPA, OAR, Air data-daily air quality tracker, 2020.

[8] Zhou, Y., Zi, T., Lang, J., Huang, D., Wei, P., Chen, D. \& Cheng, S., Impact of rural residential coal combustion on air pollution in Shandong, China. Chemosphere, 260, $127517,2020$.

[9] US Census Bureau, Decennial Census by Decades, 2019.

[10] Climatestotravel, Los Angeles climate: Average weather, temperature, precipitation, best time.

[11] Garcetti, E., COVID-19 Orders, 2020. Office of Los Angeles Mayor Eric Garcetti.

[12] Wigglesworth, A., L.A. County can reopen restaurants, barbershops, salons, Newsom says, 2020.

[13] Cuomo, A.M., Governor Cuomo Issues Guidance on Essential Services Under The 'New York State on PAUSE' Executive Order, 2020.

[14] City of New York, NYC Business Reopening Guide-NYC Business, 2020.

[15] Washington State Coronavirus Response, News, 2020.

[16] King County, Safe Start-King County, 2020.

[17] Eberwein, J.R., Homyak, P.M., Carey, C.J., Aronson, E.L. \& Jenerette, G.D., Large nitrogen oxide emission pulses from desert soils and associated microbiomes. Biogeochemistry, 149(3), pp. 239-250, 2020.

[18] Clapp, L.J. \& Jenkin, M.E., Analysis of the relationship between ambient levels of $\mathrm{O}_{3}$, $\mathrm{NO}_{2}$ and $\mathrm{NO}$ as a function of NOx in the UK. Atmospheric Environment, 35(36), pp. 6391-6405, 2001.

[19] Sun, Y. et al. Distinct impacts of light and heavy precipitation on $\mathrm{PM}_{2.5}$ mass concentration in Beijing. Earth and Space Science, 6(10), pp. 1915-1925, 2019. https://agupubs.onlinelibrary.wiley.com/doi/pdf/10.1029/2019EA000717.

[20] Bao, R. \& Zhang, A., Does lockdown reduce air pollution? Evidence from 44 cities in northern China. Science of The Total Environment, 731, 139052, 2020.

[21] Mahato, S., Pal, S. \& Ghosh, K.G., Effect of lockdown amid COVID-19 pandemic on air quality of the megacity Delhi, India. Science of The Total Environment, 730, 139086, 2020.

[22] Hashim, B.M., Al-Naseri, S.K., Al-Maliki, A. \& Al-Ansari, N., Impact of COVID19 lockdown on $\mathrm{NO}_{2}, \mathrm{O}_{3}, \mathrm{PM}_{2.5}$ and $\mathrm{PM}_{10}$ concentrations and assessing air quality changes in Baghdad, Iraq. Science of The Total Environment, 754, 141978, 2021.

[23] US EPA, Basic Information about Carbon Monoxide (CO) Outdoor Air Pollution, 2016.

[24] US EPA, Nitrogen Dioxide $\left(\mathrm{NO}_{2}\right)$ Pollution, 2016.

[25] US EPA, Ground Level Ozone Basics, 2015.

[26] Nakada, L.Y.K. \& Urban, R.C., COVID-19 pandemic: Impacts on the air quality during the partial lockdown in São Paulo state, Brazil. Science of The Total Environment, 730, 139087, 2020. 
[27] Jean-Etienne, P., The Particulars of $P M_{2.5}, 2014$.

[28] Climate United States - Monthly Averages.

[29] Venter, Z.S., Aunan, K., Chowdhury, S. \& Lelieveld, J., Air pollution declines during COVID-19 lockdowns mitigate the global health burden. Environmental Research, 192, $110403,2021$. 